\title{
Motor Development as a Potential Marker to Monitor Infantile Pompe Disease on Enzyme Replacement Therapy
}

\author{
Paula de Almeida Thomazinho', Fernanda Bertão Scalco², Maria Lúcia Costa de Oliveira², \\ Dafne Dain Gandelman Horovitz ${ }^{3}$, Juan Clinton Llerena Jr. ${ }^{3}$ \\ ${ }^{1}$ Fisioterapia Motora, Instituto Nacional de Saúde da Mulher, da Criança e do Adolescente Fernandes Figueira/FIOCRUZ, \\ Rio de Janeiro, Brasil \\ ${ }^{2}$ Departamento de Bioquímica, Universidade Federal do Rio de Janeiro, Rio de Janeiro, Brasil \\ ${ }^{3}$ Área de Centro de Genética Médica, Instituto Nacional de Saúde da Mulher, da Criança e do Adolescente Fernandes \\ Figueira/FIOCRUZ, Rio de Janeiro, Brasil \\ Email: pthomazinho@iff.fiocruz.br
}

How to cite this paper: de Almeida Thomazinho, P., Scalco, F.B., de Oliveira, M.L.C., Horovitz, D.D.G. and Llerena Jr., J.C. (2017) Motor Development as a Potential Marker to Monitor Infantile Pompe Disease on Enzyme Replacement Therapy. Open Journal of Clinical Diagnostics, 7, 819.

https://doi.org/10.4236/ojcd.2017.71002

Received: December 6, 2016

Accepted: January 14, 2017

Published: January 17, 2017

Copyright $\odot 2017$ by authors and Scientific Research Publishing Inc. This work is licensed under the Creative Commons Attribution International License (CC BY 4.0).

http://creativecommons.org/licenses/by/4.0/ (c) (i) Open Access

\begin{abstract}
After Enzyme Replacement Therapy (ERT) using recombinant human acid alpha-glucosidase (rhGAA), survival of Infantile Pompe Disease (IPD) patients through the first 18 months of age has been documented and acquisitions of motor development are an important outcome, but description of its course is scarce. Objective: To describe the motor development in an IPD patient and its correlation with clinical conditions during the first 18 months on ERT with rhGAA. Methods: By longitudinal observational study of an IPD case at early stage. Clinical and biochemical characteristics were obtained from patient records. Echocardiogram assessed cardiac indexes and the urinary biomarker-glucose tetrasaccharide $\left(\mathrm{Glc}_{4}\right)$-was obtained by HPLC/UV, following sample derivatization with butyl 4 -amino benzoate and analysis on a C18 stationary phase column. Motor skills were evaluated with Alberta Infant of Motor Scale (AIMS) and motor delay was considered as motor percentile (p) below 10. Descriptive statistical analysis was carried out and t-test was used to calculate the differences among means, with significance level defined as $p$ value $<0.05$. Results: After ERT beginning amelioration of the cardiomyopathy with reduced left ventricle mass index (LVMI) from the 2nd month onwards was observed, but above the upper normal limit for healthy children and CRIM-positive IPD patients. Although GAA antibodies level remained above the recommended titers and fluctuating elevation of $\mathrm{Glc}_{4}$ quantified, motor development analysis showed an ascendant curve expected for age within achievement of independent ambulation. Motor delay after pneumonia and maintenance of hypotonia were noted. Variation of $\mathrm{Glc}_{4}$ appeared long after a transitory intercurrence. Conclusion: In an IPD case, motor development can
\end{abstract}


have normal evolution despite hypotonia. Motor analysis seems to be sensitive to follow-up clinical intercurrences. To elucidate the interaction among prognostic factors and outcomes, further clinical studies need to be conducted.

\section{Keywords}

Infantile Pompe Disease, Motor Development, Enzyme Replacement Therapy, $\mathrm{Glc}_{4}$ Biomarker

\section{Introduction}

Pompe disease (OMIM ${ }^{1} 23230$ ), or Glycogenosis type II, is an autosomal recessive disorder resulting from acid alpha-glucosidase deficiency (GAA; 3.2.1.20) which causes lysosomal glycogen storage multi-systemically, predominant in skeletal muscle, heart tissues, nervous tissue and in the liver [1].

With the approval of Pompe disease treatment by enzyme replacement therapy (ERT) with recombinant human GAA enzyme (rhGAA) [2], there was a change in the natural history of the disease, with increased life expectancy and changes in phenotypic characteristics so far known particularly in the infantile form [3] [4] [5].

Infantile Pompe Disease (IPD) is the rarest and most severe form of the disease, with an incidence of 1:138,000 live births and onset of symptoms in the first several months of life. Clinical manifestations include hypotonia and muscle weakness, with motor development delay, massive cardiomegaly, macroglossia and hepatomegaly. Swallowing difficulties are also common, causing malnutrition, recurrent aspiration and respiratory tract infections [6] [7] [8].

Cardiac symptoms progress well with ERT treatment; however, recent studies suggest that muscle involvement seems not to reverse completely, regardless of the medication dose used [8] [9].

Monitoring the IPD patients' progression on ERT is recommended by Pompe's management guidelines [7] [10], with clinical reviews at every 6 months in children under 5 years and using scales and assessment protocols of child development. Motor follow-up through standardized scales is critical to evaluate the outcomes with ERT [7] [11], but this issue was currently used only in terms of motor acquisitions as an important endpoint.

This study aimed to describe the characteristics of motor development evaluation of a child with IPD on early ERT scheme, outside clinical trials and its relationship with clinical conditions during the first 18 months of life, as a potential marker of disease.

\section{Methodology}

For the purpose of the subject clinical characteristics of a patient with good

${ }^{1}$ OMIM: Online Mendelian Inheritance in Man. This is a compendium of human genes and genetic diseases, with particular emphasis on the molecular relationship between genetic variation and phenotypic expression. 
treatment response were described as well as the aspects of her motor development and other laboratory results, in follow-up of 18 months. ERT with recombinant human acid $\alpha$-glucosidase (alglucosidase alfa-Myozyme ${ }^{\oplus}$; Genzyme, Cambridge, MA) was prescribed based on the IPD diagnosis and in standard recommended dose of $20 \mathrm{mg} / \mathrm{kg}$ in every 2 weeks.

Motor development was assessed through observation and recording of motor skills showed by the child, using the Alberta Infant Motor Scale (AIMS) [12]. Motor assessments were carried out on the same day as ERT during follow-up period.

Raw score was obtained by adding the total items observed in the four positional scores-prone, supine, sitting and standing. Derived score in relation to normative sample were obtained considering the chronological age corrected to 40 weeks as recommended by AIMS [12]. Motor delay was considered as values of motor percentile (p) below 10 .

The cardiac involvement was evaluated by echocardiography to assess left ventricular mass index (LVMI) in $\mathrm{g} / \mathrm{m}^{2}$ and ejection fraction (EF). They were performed at baseline and in five more times during treatment period.

The ERT response may also be assessed biochemically using glucose tetrasaccharide $\left(\mathrm{Glc}_{4}\right)$ biomarker. Biomarkers are molecules that indicate the presence or the extent of a biological process that is directly related to clinical manifestations of a particular disease [13] [14]. $\mathrm{Glc}_{4}$ is a limiting dextrin resulting from glycogen degradation, which has a good correlation with the level of glycogen accumulation in skeletal and cardiac muscles and with the ERT response. It is currently used as a co-adjuvant tool for the diagnosis of IPD and more recently in studies for overall assessment of disease severity [8] [15] [16].

The quantitative analysis of urinary $\mathrm{Glc}_{4}$ was performed by HPLC/UV followed by derivatization with butyl 4-amino benzoate and subsequent analysis on a C18 column (adapted from An et al. [17]). Biochemical analyses of $\mathrm{Glc}_{4}$ were carried out at diagnosis and from some months onwards at regular intervals (every 1 - 2 months) during the year's course of the ERT.

Other clinical characteristics and complications, as anti-Myozyme antibodies titers and hospitalization period, were observed.

Data analysis was carried out by descriptive statistics and t-test to calculate the differences among means, with significance level defined as $p$ value $<0.05$. To compare the evolution before and after the clinical intercurrence, time and amplitude differences of motor assessment (raw score) and urinary biomarker $\left(\mathrm{Glc}_{4}\right)$ was measured in relative values, by the subtraction of the final point from the initial point. Positive and negative values were obtained as results of the increase or decrease measures respectively.

Construction of charts was made in Excel ${ }^{\circ} 2010$. To standardize data, charts were built with the chronological age of the events although motor analysis was carried out with corrected age, as mentioned above.

The study was approved by the Ethical Committee Board (CAAE no. 
02109812.6.1001.5269). Informed consent was obtained from patient's parents authorizing the use of ERT, biochemical analysis in the urine, motor assessments as well as access to her medical records.

\section{Results}

Female infant, with a birth weight of 3085 g, prematurely born at 36 weeks of gestational age, non-consanguineous parents, was referred to the Medical Genetics Center of Maternal-infant Hospital in Rio de Janeiro (Brazil) with hypertrophic cardiomegaly and muscle hypotonia. Family history of a brother deceased at the age of four months with IPD.

The diagnosis was confirmed by GAA activity analysis at two months of life, with an abnormal inhibition in dried blood spot and $0.25 \mathrm{nmol} /(\mathrm{mg}$ protein $\times \mathrm{h})$ in leukocytes, four times lower than the minimum reference value. A biceps muscle biopsy showed significant involvement of muscle fibers (90\%) at the same age, revealing massive glycogen accumulation. No problems were detected on sucking function or on sucking-swallowing coordination at diagnosis.

Genotyping revealed presence of two pathogenic mutations in the GAA gene, characterizing the patient as a compound heterozygote (c2560 > T, p.Arg854X; c2501-2502delCApThr834Argfs49X). Cross-reactive immunologic material (CRIM) was positive.

ERT was then initiated, with the administration of human recombinant enzyme GAA at the dosage of $20 \mathrm{mg} / \mathrm{kg}$ biweekly as recommended by the manufacturer and hadn't been disrupted during study period.

Initial cardiac examination showed severe hypertrophy of the left ventricle (LV) without systolic or diastolic dysfunction or LV outflow obstruction. The progression of cardiac involvement was good, as shown in Figure 1, by LV mass index (LVMI) $\left(\mathrm{g} / \mathrm{m}^{2}\right)$ and ejection fraction (EF). The mean of LV cardiac mass was $50.7( \pm 13.76) \mathrm{g}$ with mean LVMI of $139.28( \pm 53.86) \mathrm{g} / \mathrm{m}^{2}$ and mean EF of $69.5 \%$.

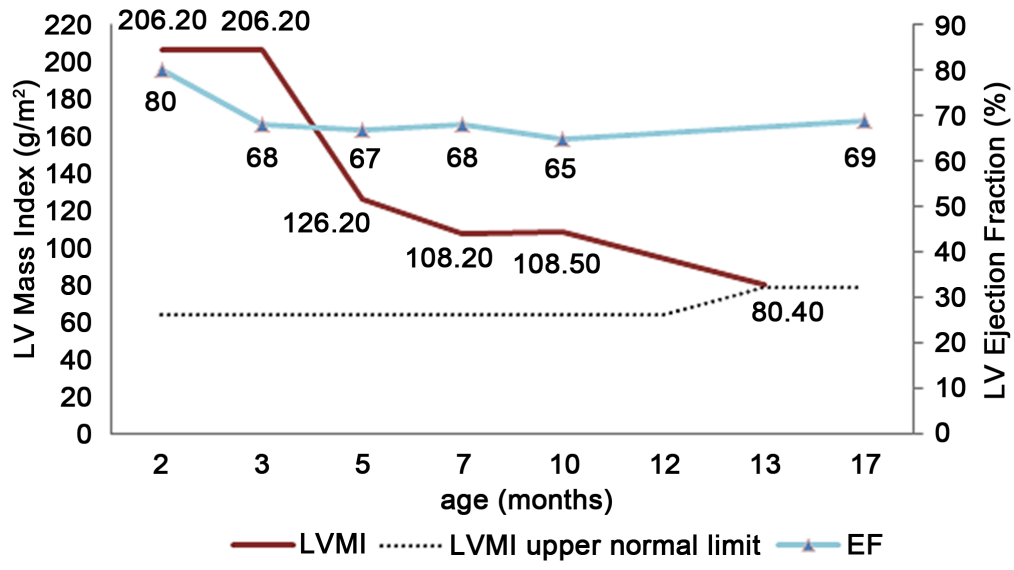

Figure 1. Progression of cardiac indexes during ERT treatment period for the IPD patient. EF: ejection fraction; LVMI: LV mass index, abnormality defined as $\geq 65 \mathrm{~g} / \mathrm{m}^{2}$ for patients up to 12 months old or $>79 \mathrm{~g} / \mathrm{m}^{2}$ for children $>12$ months old) [18]. 
Anti-Myozyme antibodies titers ( $\log 1 /$ anti-GAA $\operatorname{IgG})$ were assessed at 9 months of life ( 7 months after initiating ERT), by Genzyme Corporation, using enzyme-linked immunosorbent assay and maintained values of 1:3200 during the study period, in a total of 36 ERT infusions performed.

Baseline urinary Glc4 was $63.46 \mathrm{mmol} / \mathrm{mol}$ creatinine $(\mathrm{CN})$, corresponding to 2.07 times the age-matched control values (upper normal limit for age $\leq 12$ months of $30.60 \mathrm{mmol} / \mathrm{mol} \mathrm{CN}$ ). The mean level of Glc4 during the study was $47.74 \mathrm{mmol} / \mathrm{mol} \mathrm{CN}$, with no statistically significant differences between the first and second years of age (t-test; $p=0.96$ ), although with a slight decreasing trend during the period considered.

There was a motor delay at diagnosis, but infant gross motor development was in the normal range after initiating ERT in the majority of assessments despite muscle hypotonia. The first drop in raw score occurred when the productive cough emerged at 7.6 months of age; at last one month after a second drop before aspiration pneumonia with brief hospitalization (four days) occurred. Gross motor delay could be identified with a significant drop in percentile scores $(p<10)$ only one month after this clinical intercurrence, with persistent productive cough.

Considering the corrected age to achieve motor milestones the child sat without support at seven months, took her first steps at 14 months, achieving independent gait at 17 months, full-time without the use of any assistive devices, although still with broad-based stand.

The motor development assessments are shown with urinary Glc4 levels for the study period in Figure 2.

The correlation among motor development and the other clinical variables couldn't be done with statistic tests. Nevertheless comparing the differences obtained in paired points of motor development and urinary biomarker $\mathrm{Glc}_{4}$ a tendency to greater sensitivity in the first variable in relation to clinical conditions was observed (Figure 3 and Table 1).

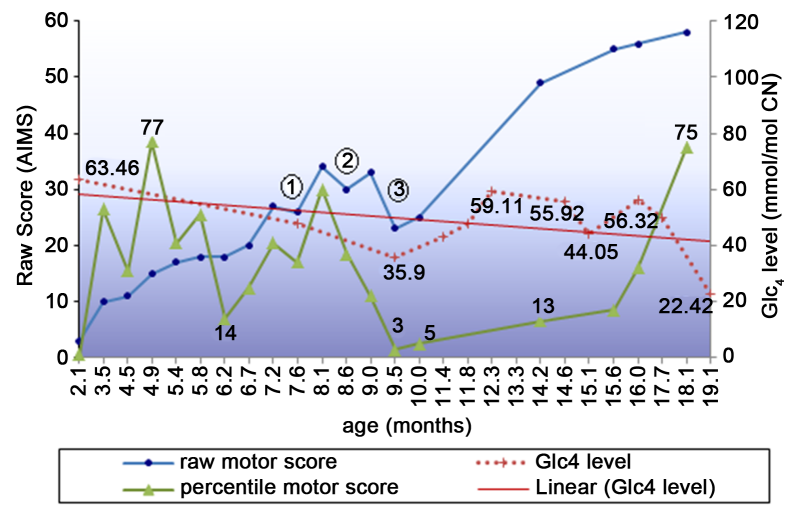

Figure 2. Motor assessments in raw and derived scores and dosage of urinary biomarker Linear ( $\mathrm{Gl}_{4}$ level) distributed by chronological age. (1) (2) Drops in raw score during the study period; (3) Marked drop in raw score with significant motor delay. (Upper normal limit for age $\leq 12$ months of $30.60 \mathrm{mmol} / \mathrm{mol} \mathrm{CN}>1$ to 5 years of $9.72 \mathrm{mmol} / \mathrm{mol} \mathrm{CN}$, according to the Laboratory of Inborn Errors of Metabolism, Rio de Janeiro's Federal University unpublished data). 


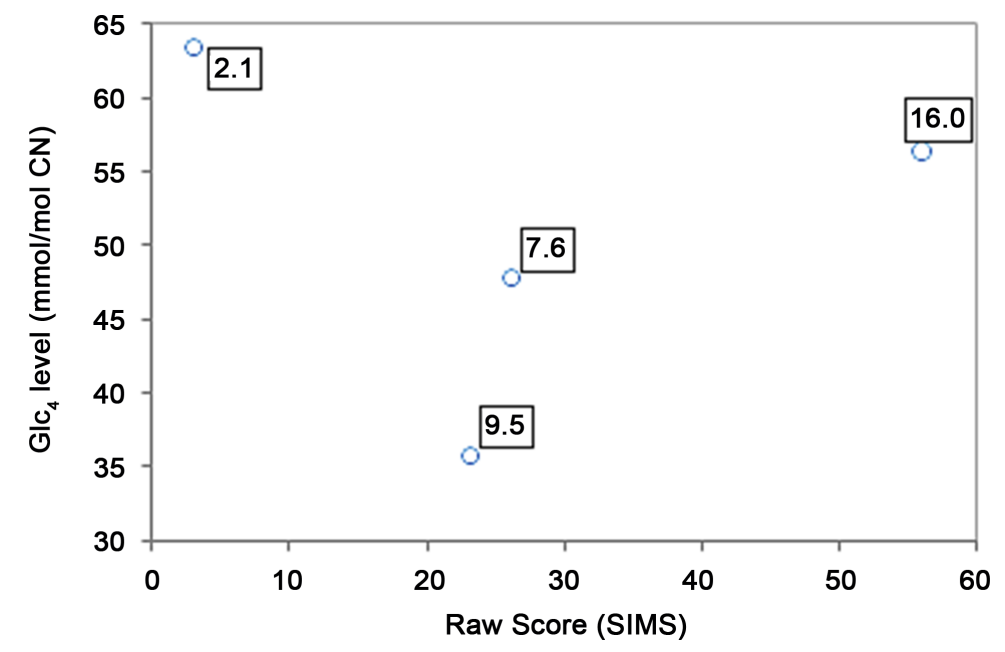

Figure 3. Paired points of motor assessment (raw score) and urinary biomarker $\left(\mathrm{Glc}_{4}\right)$ measured by age.

Table 1. Paired points' differences $(\Delta)$ measured in relative values by age, motor assessment (raw score) and urinary biomarker $\left(\mathrm{Glc}_{4}\right)$.

\begin{tabular}{|c|c|c|c|c|c|c|c|}
\hline & & $\Delta$ & & $\Delta^{*}$ & & $\Delta$ & \\
\hline $\begin{array}{c}\text { Age } \\
\text { (months) }\end{array}$ & 2.1 & 5.5 & 7.6 & 1.9 & 9.5 & 5.5 & 16.0 \\
\hline Raw Score (AIMS) & 3 & 23 & 26 & -3 & 23 & 33 & 56 \\
\hline $\begin{array}{c}\mathrm{Glc}_{4} \text { Level } \\
(\mathrm{mmol} / \mathrm{mol} \mathrm{CN})\end{array}$ & 63.46 & $\overline{-15.62}$ & 47.84 & $\overline{-11.94}$ & 35.9 & $\overline{20.42}$ & 56.32 \\
\hline
\end{tabular}

${ }^{\star}$ During this interval occurred a hospitalization due to aspiration pneumonia.

Appropriate oral function and nutritional status was maintained with exclusive breastfeeding up to six months of life, progressing to swallowing in coordination and gastrostomy at the age of 1 year and 8 months. Sialorrhea and language delay were observed during the follow-up period, possibly associated with facial hypotonia, despite the shy and introspective child behavior. Audiometric evaluation was not performed during the study period but no deficit in listening ability was clinically noted.

\section{Discussion}

After ten years of treatment classical Infantile Pompe Disease still remains a life-threatening condition associated with high morbidity and large variability. Several prognostic factors are recognized in patients with IPD, among which residual GAA enzyme level, age at beginning of ERT treatment, CRIM status, extent of initial muscle damage and maintenance of high antibody titers may be of importance [19] [20] [21].

The case discussed here refers to a Brazilian patient at early stage IPD on ERT, with detailed description of gross motor progression. In Brazil only another IPD case on ERT with evaluation of motor developmental skills has been published, 
however in an advanced stage of the disease, with ventilator-assistance dependence, and without a detailed description of the functional and motor development [22].

The ERT treatment with rhGAA in our patient resulted in an improvement of the cardiomyopathy with reduced LVMI from the 2nd month onwards; although it remained above the upper normal limit for healthy children [18], it was similar to IPD patients studied. For CRIM-positive patients with IPD the mean LVMI of $76.5 \mathrm{~g} / \mathrm{m}^{2}$ after 12 months and $63.7 \mathrm{~g} / \mathrm{m}^{2}$ after 24 months on ERT have been reported [23].

The GAA antibodies level remained in the median peak found in CRIM-positive patients with IPD [23]; however above the recommended titers (log1/antiGAA IgG $\leq 1: 1600$ ) after 12 months on ERT [21]. Nevertheless, our patient had a satisfactory clinical progression and a good response to ERT was observed. Reports of the literature describe greater decrease in antibody titers after 23 months on ERT [23].

Changes in urinary $\mathrm{Glc}_{4}$ were also associated with clinical response. The initial drop in $\mathrm{Glc}_{4}$ excretion could be identified as relating to improvement of LVMI suggesting rapid reduction in cardiac muscle glycogen content after initiating ERT, as was described in literature [17] [23]. The decrease in the mean urinary $\mathrm{Glc}_{4}$ level compared with baseline at $1-2$ months and at 13 months was significant associated with clinical improvements in IPD patients in first year of ERT with amelioration of the cardiomyopathy (as measured by LVMI) and achievement of independent ambulation [17]. However the $\mathrm{Glc}_{4}$ trend levels in the case reported were very high and always above the ideal normal upper limit for age, with fluctuating elevation, which was associated with a less favorable motor response and an improved motor function [17].

At 13 months of age the urinary $\mathrm{Glc}_{4}$ level was slightly below the baseline value. The best level of $\mathrm{Glc}_{4}$ was found at 17 months after initiating ERT with absolute value and linear trend similar to the literature [23].

Motor assessments by AIMS showed that the child motor development was appropriate with the normative sample for most of the study period, with acquisition of all motor milestones expected for age. Throughout the follow-up, family was instructed to perform stimulation activities at home suitable for each stage of development which may also have contributed to the good response obtained. But the detailed analysis showed the high importance of motor evolution to monitor the clinical status and the disease evolution. This reinforces the need for specialized periodic monitoring, particularly important for infants, who are in a crucial period for neurological development and at risk for clinical intercurrences.

The presence of respiratory disease at eight-nine months even for a brief period was, coincidentally or not marked by a motor impact before and after hospital discharge with decreases in the motor evaluation, gives not only the suggestive influence of the general clinical status on the motor skills but a potential identification to hers clinical worsening due to bulbar involvement that could 
contribute to gastrostomy one year later. This event may also added to dropping the percentile observed at 12 months (p13) compared with the median provided by another study on IPD (p33) [23]. In fact the relation between pneumonia and bulbar involvement needs attention.

The maintenance of hypotonia and slow motor responses could be observed through clinical evaluation tests such as muscle tone and posture adjustment reaction. Such subtleties were also described by other authors [23] [24].

A decrease in muscle contraction speed could be associated with greater impairment of type II muscle fibers (fast twitch muscles) which are prevalent in IPD patients $\leq 17$ months of age in both genders [25] [26]. However it is still unclear whether this fiber distribution would be physiological, due to the maturation process and differentiation of muscle fibers, or related to IPD. Furthermore less glycogen clearance in type II muscles fibers compared to Type I fibers through ERT in the Pompe disease mouse model has been notice [27]. Whether there is a predominance of involvement among different types of muscle fibers in the pathophysiology of the disease is still unclear [9] [26].

Another important aspect refers to the fluctuation in derived motor scores obtained during the follow-up period. In contrast to growth aspects typical motor development does not show linear trajectory with intraindividual variabilities [28]. The speed of motor acquisition is not uniform and changes in percentage scores over time are not constant among individuals. With regard to gross motor performance, the literature suggests a concave shape curve to the percentage scores from 9 months [28], similar to those found in our patient.

Thus periods of low percentile scores in the normal range can portray only a temporary phase where new skills have not yet emerged [28]. Experience has shown that the major alert level was when a drop in activities (raw score) was observed, especially considering the progressive muscular disease. This reinforces that, particularly in early life, a close monitoring of motor development is essential as recommended for infants at risk in a more frequently assessment intervals for each every month. Approaches to a detailed analysis of motor development include specialized observations of movement components and perception by parents, in addition to the use of standardized assessment measures [29].

No correlation could be established among declining periods of gross motor abilities and acute disease process or increased $\mathrm{Glc}_{4}$, because the few paired points prejudiced the use of statistical correlation tests as previously mentioned. Although different variances in response time were noted among motor scores and urinary $\mathrm{Glc}_{4}$ levels up to and after hospitalization.

Increased $\mathrm{Glc}_{4}$ excretion was measured afterwards pneumonia during three consecutive months. This could be related to a greater muscle demand for the chronological motor acquisition period with activities as the standing position, increased mobility and secondary muscle damage. Another hypothesis is that the muscle glycogen buildup could be depend to the poor general clinical condition of the patient and higher energy consumption needed during an extended period. 


\section{Conclusion}

The motor evolution assessment in IPD case could be a potential disease marker even though it expressed a normal acquisition of all motor milestones. Motor development analysis seems to be sensitive to follow-up clinical intercurrences in our patient. There were particular aspects as hypotonia and slow motor responses identified. Those characteristics strengthen the importance of motor development as an essential tool to monitor the IPD progression particularly for developing countries with difficulties to provide all indicated measures. No statistic correlation could be established among motor developmental abilities in IPD and urinary Glc4 analysis or any other clinical variables. To elucidate the interaction among prognostic factors and outcomes, further clinical studies need to be conducted.

\section{Acknowledgements}

To Dr. Priya Kishnani, Dr. Deeksha Bali and colleagues at the Division of Medical Genetics, Department of Pediatrics, Duke University Medical Center, Durham, North Carolina, who kindly performed the cross-reactive immunologic material test.

\section{Conflict of Interest}

One author is a member of the Pompe Disease Advisory Board for Genzyme, A Sanofi Company.

\section{References}

[1] Hirschhorn, R. and Reuser, A.J.J. (2001) Glycogen Storage Disease Type II: Acid Alphaglucosidase (Acid Maltase) Deficiency. In: Scriver, C.R., Beaudet, A.L., Sly, W.S. and Valle, M.D., Eds., The Metabolic and Molecular Bases of Inherited Disease, McGraw-Hill, New York, 3389-3420.

[2] U.S. Food and Drug Administration (2006) First Treatment for Pompe Disease. FDA Consumer Magazine, 2-3.

[3] Kishnani, P.S., Beckemeyer, A.A. and Mendelsohn, N.J. (2012) The New Era of Pompe Disease: Advances in the Detection, Understanding of the Phenotypic Spectrum, Pathophysiology, and Management. American Journal of Medical Genetics Part C: Seminars in Medical Genetics, 160C, 1-7. https://doi.org/10.1002/ajmg.c.31324

[4] Chien, Y.-H., Lee, N.-C., Thurberg, B.L., Chiang, S.-C., Zhang, X.K., Keutzer, J., et al. (2009) Pompe Disease in Infants: Improving the Prognosis by Newborn Screening and Early Treatment. Pediatrics, 124, e1116-e1125. https://doi.org/10.1542/peds.2008-3667

[5] Howell, R.R., Byrne, B., Darras, B.T., Kishnani, P., Nicolino, M. and van der Ploeg, A. (2006) Diagnostic Challenges for Pompe Disease: An Under-Recognized Cause of Floppy Baby Syndrome. Genetics in Medicine, 8, 289-296. https://doi.org/10.1097/01.gim.0000204462.42910.b8

[6] Kishnani, P.S., Hwu, W.-L., Mandel, H., Nicolino, M., Yong, F. and Corzo, D. (2006) A Retrospective, Multinational, Multicenter Study on the Natural History of Infantile-Onset Pompe Disease. Journal of Pediatrics, 148, 671-676. 
https://doi.org/10.1016/j.jpeds.2005.11.033

[7] Kishnani, P.S., Steiner, R.D., Bali, D., Berger, K., Byrne, B.J., Case, L.E., et al. (2006) Pompe Disease Diagnosis and Management Guideline. Genetics in Medicine, 8, 267-288. https://doi.org/10.1097/01.gim.0000218152.87434.f3

[8] Chien, Y.-H., Lee, N.-C., Chen, C.-A., Tsai, F.-J., Tsai, W.-H., Shieh, J.-Y., et al. (2015) Long-Term Prognosis of Patients with Infantile-Onset Pompe Disease Diagnosed by Newborn Screening and Treated since Birth. Journal of Pediatrics, 166, 985-991. https://doi.org/10.1016/j.jpeds.2014.10.068

[9] Prater, S.N., Patel, T.T., Buckley, A.F., Mandel, H., Vlodavski, E., Banugaria, S.G., et al. (2013) Skeletal Muscle Pathology of Infantile Pompe Disease during Long-Term Enzyme Replacement Therapy. Orphanet Journal of Rare Diseases, 8, 90.

https://doi.org/10.1186/1750-1172-8-90

[10] Llerena, J.C., Horovitz, D.M., Nagahashi Marie, S.K., Porta, G., Giugliani, R., Muñoz Rojas, M.V., et al. (2009) The Brazilian Consensus on the Management of Pompe Disease. Journal of Pediatrics, 155, S47-S56.

https://doi.org/10.1016/j.jpeds.2009.07.006

[11] Savegnago, A.K., da Silva, R.M., Jonhston, C., Martins, A.M., Melo, A.P.L., Carvalho, W.B., et al. (2012) Systematic Review of Functional Assessment Scales in Pompe Disease. Revista Paulista de Pediatria, 30, 272-277. https://doi.org/10.1590/S0103-05822012000200018

[12] Piper, M.C. and Darrah, J. (1994) Motor Assessment of the Developing Infant. United States. WB Saunders Company, Philadelphia, 210 p.

[13] Aerts, J., Kallemeijn, W.W., Wegdam, W., Joao Ferraz, M., van Breemen, M.J., Dekker, N., et al. (2011) Biomarkers in the Diagnosis of Lysosomal Storage Disorders: Proteins, Lipids, and Inhibodies. Journal of Inherited Metabolic Disease, 34, 605-619. https://doi.org/10.1007/s10545-011-9308-6

[14] Suomalainen, A. (2011) Biomarkers for Mitochondrial Respiratory Chain Disorders. Journal of Inherited Metabolic Disease, 34, 277-282. https://doi.org/10.1007/s10545-010-9222-3

[15] Young, S.P., Zhang, H., Corzo, D., Thurberg, B.L., Bali, D., Kishnani, P.S., et al. (2009) Long-Term Monitoring of Patients with Infantile-Onset Pompe Disease on Enzyme Replacement Therapy Using a Urinary Glucose Tetrasaccharide Biomarker. Genetics in Medicine, 11, 536-541. https://doi.org/10.1097/GIM.0b013e3181a87867

[16] Young, S.P., Piraud, M., Goldstein, J.L., Zhang, H., Rehder, C., Laforet, P., et al. (2012) Assessing Disease Severity in Pompe Disease: The Roles of a Urinary Glucose Tetrasaccharide Biomarker and Imaging Techniques. American Journal of Medical Genetics Part C: Seminars in Medical Genetics, 160C, 50-58.

https://doi.org/10.1002/ajmg.c.31320

[17] An, Y., Young, S.P., Kishnani, P.S., Millington, D.S., Amalfitano, A., Corzo, D., et al. (2005) Glucose Tetrasaccharide as a Biomarker for Monitoring the Therapeutic Response to Enzyme Replacement Therapy for Pompe Disease. Molecular Genetics and Metabolism, 85, 247-254. https://doi.org/10.1016/j.ymgme.2005.03.010

[18] Vogel, M., Staller, W. and Bühlmeyer, K. (1991) Left Ventricular Myocardial Mass Determined by Cross-Sectional Echocardiography in Normal Newborns, Infants, and Children. Pediatric Cardiology, 12, 143-149. https://doi.org/10.1007/BF02238520

[19] Kroos, M., Hoogeveen-Westerveld, M., van der Ploeg, A. and Reuser, A.J. (2012) The Genotype-Phenotype Correlation in Pompe Disease. American Journal of Medical Genetics Part C: Seminars in Medical Genetics, 160C, 59-68. https://doi.org/10.1002/ajmg.c.31318 
[20] Kishnani, P.S., Goldenberg, P.C., DeArmey, S.L., Heller, J., Benjamin, D., Young, S., et al. (2010) Cross-Reactive Immunologic Material Status Affects Treatment Outcomes in Pompe Disease Infants. Molecular Genetics and Metabolism, 99, 26-33. https://doi.org/10.1016/j.ymgme.2009.08.003

[21] Banugaria, S.G., Prater, S.N., Ng, Y.-K., Kobori, J.A., Finkel, R.S., Ladda, R.L., et al. (2011) The Impact of Antibodies on Clinical Outcomes in Diseases Treated with Therapeutic Protein: Lessons Learned from Infantile Pompe Disease. Genetics in Medicine, 13, 729-736. https://doi.org/10.1097/GIM.0b013e3182174703

[22] Pereira, S.J. and Berditchevisky, C.R. (2008) Report of the First Brazilian Infantile Pompe Disease Patient to Be Treated with Recombinant Human Acid Alpha-Glucosidase. Journal of Pediatrics, 84, 272-275.

[23] Prater, S.N., Banugaria, S.G., DeArmey, S.M., Botha, E.G., Stege, E.M., Case, L.E., et al. (2012) The Emerging Phenotype of Long-Term Survivors with Infantile Pompe Disease. Genetics in Medicine, 14, 800-810. https://doi.org/10.1038/gim.2012.44

[24] Case, L.E., Beckemeyer, A.A. and Kishnani, P.S. (2012) Infantile Pompe Disease on ERT-Update on Clinical Presentation, Musculoskeletal Management, and Exercise Considerations. American Journal of Medical Genetics Part C: Seminars in Medical Genetics, 160C, 69-79. https://doi.org/10.1002/ajmg.c.31321

[25] Matsunaga, E.M. (2009) Muscle Fiber Type Distribution and Genotype Correlation in the Pompe Disease. Dissertação, Faculdade de Medicina da Universidade de São Paulo, São Paulo.

[26] van den Berg, L.E.M., Drost, M.R., Schaart, G., de Laat, J., van Doorn, P.A., van der Ploeg, A.T., et al. (2013) Muscle Fiber-Type Distribution, Fiber-Type-Specific Damage, and the Pompe Disease Phenotype. Journal of Inherited Metabolic Disease, 36, 787-794. https://doi.org/10.1007/s10545-012-9541-7

[27] Raben, N., Danon, M., Gilbert, A.L., et al. (2003) Enzyme Replacement Therapy in the Mouse Model of Pompe Disease. Molecular Genetics and Metabolism, 8, 156169. https://doi.org/10.1016/j.ymgme.2003.08.022

[28] Darrah, J., Senthilselvan, A. and Magill-Evans, J. (2009) Trajectories of Serial Motor Scores of Typically Developing Children. Infant Behavior \& Development, 32, 72 78. https://doi.org/10.1016/j.infbeh.2008.10.001

[29] Council on Children with Disabilities, Section on Developmental Behavioral Pediatrics (2006) Identifying Infants and Young Children with Developmental Disorders in the Medical Home: An Algorithm for Developmental Surveillance and Screening. Pediatrics, 118, 405-720. https://doi.org/10.1542/peds.2006-1231 


\section{Abbreviations}

AIMS: Alberta Infant of Motor Scale

CRIM: Cross-reactive immunologic material

EF: Ejection fraction

ERT: Enzyme replacement therapy

GAA: Acid $\alpha$-glucosidase

Glc4: Glucose tetrasaccharide

IPD: Infantile Pompe Disease

LV: Left ventricle

LVMI: Left ventricle mass index

p: Motor percentile

rhGAA: Recombinant human acid $\alpha$-glucosidase

Submit or recommend next manuscript to SCIRP and we will provide best service for you:

Accepting pre-submission inquiries through Email, Facebook, LinkedIn, Twitter, etc. A wide selection of journals (inclusive of 9 subjects, more than 200 journals)

Providing 24-hour high-quality service

User-friendly online submission system

Fair and swift peer-review system

Efficient typesetting and proofreading procedure

Display of the result of downloads and visits, as well as the number of cited articles

Maximum dissemination of your research work

Submit your manuscript at: http://papersubmission.scirp.org/

Or contact ojcd@scirp.org 